\title{
El Monumento de los Mártires DE la Libertad de Alicante: Una disputa ENTRE MEMORIA Y OLVIDO
}

The Monument to the Martyrs of Freedom in Alicante: a Dispute between Memory and Oblivion

\section{José Miguel Santacreu Soler \\ Universitat d'Alacant}

RESUMEN: La disputa entre la memoria y el olvido es la base de la edificación de las sociedades y de la ciudad. Donde una avanza el otro retrocede y viceversa. Este artículo analiza la disputa entre la memoria y el olvido del Monumento de los Mártires de la Libertad de Alicante destruido por las autoridades franquistas.

PalABRAS ClaVE: memoria histórica monumental, represión franquista, recuperación, olvido.

RESUM: La disputa entre la memòria i l'oblit és la base de l'edificació de les societats i de la ciutat. On l'una avança, l'altre recula, i viceversa. Aquest article analitza la disputa entre la memòria i l'oblit del monument dels Màrtirs de la Llibertat d'Alacant, destruït per les autoritats franquistes.

PaRAUles CLAU: memòria històrica monumental, repressió franquista, recuperació, oblit.

ABSTRACT: The conflict between memory and oblivion is the foundation on which societies and cities are built. Where one goes forwards the other goes backwards and vice versa. This article analyzes the dispute between memory and oblivion of the Monument to the Martyrs of Freedom, which was destroyed by Franco's authorities. 
KEYWORDS: historical memory of monuments, Franco's repression, recovery, oblivion.

\section{Introducción}

La Guerra Civil española de 1936 terminó el 1 de Abril de 1939 en el puerto marítimo de Alicante, concretamente entre el monumento de los Mártires de la Libertad y el acceso a las dársenas. Éste fue el lugar donde se rindieron los últimos combatientes republicanos a las tropas vencedoras. En una fotografía testimonial sobre dicho día, que ilustra la tapa del libro Una presó amb vistes al mar. El drama del port d Alacant, març de 1939 (Santacreu [ed.], 2008) donde diversos autores examinan la tragedia allí vivida por más de 15000 republicanos, se ve a los soldados del ejército de ocupación que rodean el monumento y a los vencidos que se agolpan en el puerto esperando unos barcos que nunca llegaron para huir.

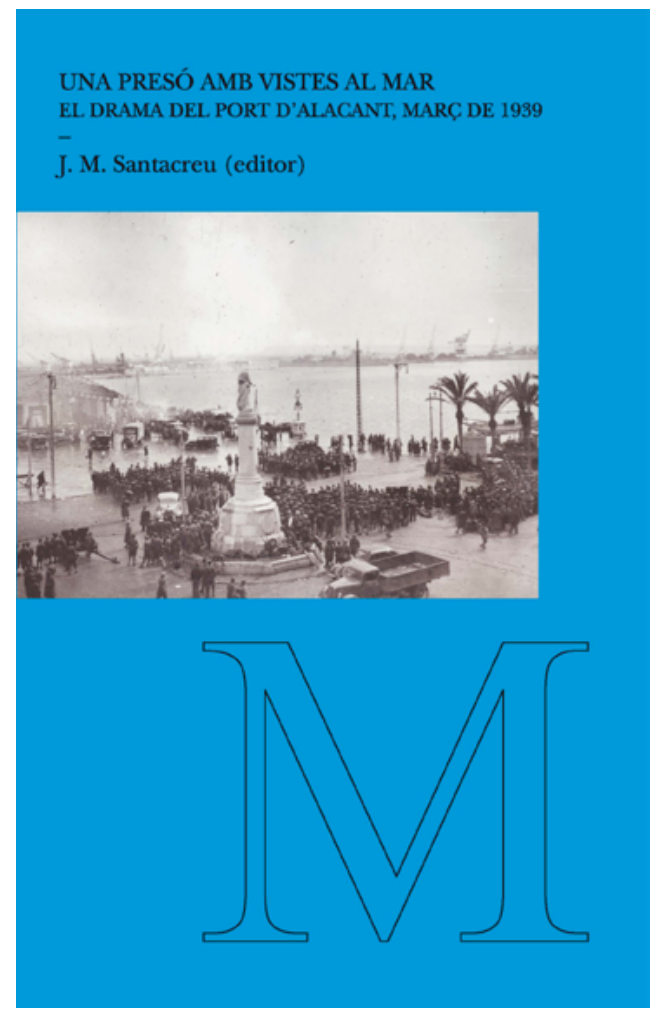


Lo que quiero destacar aquí no es el hecho del final de la guerra en el puerto de Alicante ni la desesperación de los vencidos, que fueron capturados, encerrados y en muchos casos fusilados y sepultados en fosas comunes sin lápida para identificarlos, sino el monumento de los Mártires de la Libertad rodeado por las tropas vencedoras, que ya había sido decapitado por las bombas durante la guerra.

\section{La disputa entre memoria y olvido del monumento}

El monumento seguía en pie una vez finalizada la guerra, aunque por poco tiempo. Las nuevas autoridades franquistas que tomaron posesión del gobierno de la ciudad decidieron en sesión municipal desmontarlo y borrar la memoria de dicho lugar emblemático, en el que se iniciaban las marchas de las manifestaciones reivindicativas y se honraba el recuerdo de los revolucionarios liberales del siglo XIX. Cambiaron incluso el nombre del Paseo de los Mártires de la Libertad rotulado en 1868, cuya entrada presidía desde 1914 la estatua emplazada sobre un enorme pedestal, por el de Explanada de España, hoy símbolo emblemático de la ciudad turística.

En la historia occidental anterior al siglo xx conocemos numerosas destrucciones de monumentos, retratos e inscripciones de emperadores, príncipes y señores, pero ninguno que implique la propia imagen de la ciudad. Según el director del proyecto «Iconografía de la ciudad europea» de la Maison des Sciences de l'Homme (París), Cesare de Seta (2002: 354-356), la destrucción de la memoria puede abatirse sobre uno de los protagonistas pero no puede implicar el poder ejercido por la memoria de la ciudad; sin embargo, el mundo contemporáneo se ha visto afectado por trastornos autolesivos de la identidad colectiva. Los regímenes totalitarios de Mussolini y Hitler querían legar una Roma y un Berlín distintos a los de la memoria colectiva que ellos detestaban. Querían construir unas ciudades huella y sueño imperecedero de su paso por la historia; pero «los trastornos de estos dictadores provocaron menos daños de los que pretendían causar» (Cesare de Seta, 2002: 354-356). Evidentemente; porque el fascismo y el nazismo fueron derrotados en Italia y Alemania al final de la Segunda Guerra Mundial. 
El régimen de Franco no pudo erigir monumentos y edificios gigantescos como los dictadores citados debido a sus problemas económicos internos (Llorente, 2002, 159). El Valle de los Caídos fue una excepción. Sin embargo, Franco ganó la guerra a diferencia de Hitler o Mussolini y sí que pudo convertir la ciudad en un gran monumento emblema con inversiones escasas para modelar unas ciudades huella y sueño imperecedero de su paso por la Historia. Cambiaron el nombre de las vías urbanas, concibieron avenidas imperiales y plazas de la victoria sin grandes construcciones. Erigieron estatuas del «generalísimo salvador de España» y monumentos dedicados fundamentalmente a la guerra. Los nominados fueron escasos —el general Mola y los fundadores de la Falange y de las Juntas de Ofensiva Nacional Catolicista - mientras que los más abundantes estuvieron dedicados a los «caídos por Dios y por España» colectivamente, los cuales proliferaron tanto que se identifican con el franquismo y vinculan lo civil, lo militar y lo religioso con sus símbolos y cruces. Las listas de los caídos en cruces, en lápidas colectivas, en monolitos y sobre todo en las paredes de las iglesias evocaban un amanecer que había exigido muchas vidas, cuyos dueños conocían así la honra del rescate y gozaban del túmulo de la memoria.

La política monumental del régimen ya estaba perfilada antes de terminar la guerra. La orden de 18 de febrero de 1938 (воЕ 22/02/1938) creó la Comisión de Estilo en las Conmemoraciones de la Patria con el objetivo siguiente:

La experiencia de otros países visitados por la guerra, y la que ya entre nosotros nos ha empezado a aleccionar, muestra los peligros, a veces irreparables, siempre de largos y difíciles cura y alivio, que para el decoro estético y hasta para la dignidad civil de las grandes urbes como de las modestas aldeas, significa el dejar abandonado a la iniciativa particular o a la espontánea y frecuentemente poco avisada de las corporaciones locales, cuanto se refiere al estilo y realización de monumentos patrióticos, memoriales a los caídos, inscripciones lapidarias y otras formas materiales de homenaje, destinadas a multiplicarse, sin duda, y a través de las cuales aparece muchas veces retrospectivamente tocada la epopeya en caricatura.

Una vez finalizada la guerra, el Ministerio de la Gobernación mediante la orden de 7 de agosto de 1939 (вОЕ 22/08/1939) dispuso que quedase supe- 
ditada a la aprobación de este Ministerio toda iniciativa de monumentos en general con el siguiente objetivo:

Dar unidad de estilo y de sentido a la perpetuación por monumentos de los hechos y personas de la Historia de España, y en especial a los conmemorativos de la guerra y en honor de los caídos y para evitar que el entusiasmo, justificado en muchas ocasiones, pueda regir caprichosamente esta clase de iniciativas, sembrando desilusiones cuando se trata de proyectos no viables.

El resultado es conocido por todos y estuvo vigente incluso muchos años después de la muerte del dictador. La pervivencia de algunos testimonios monumentales del franquismo, quizá demasiados, y numerosos elementos sutiles lo atestiguan. Éstos convirtieron la ciudad en un gran monumento emblema cuya continuidad estuvo presente en una España Monarquía Parlamentaria regulada por la Constitución de 1978. La reciente Ley 52/2007 de Memoria Histórica ha dado la posibilidad a las administraciones públicas para tomar las medidas oportunas para la retirada. Valga como ejemplo la suerte de la estatua ecuestre de Franco que fue retirada de la plaza del Ayuntamiento de Valencia y emplazada en el patio del Cuartel General del Ejército en dicha ciudad en 1983. Allí ha permanecido hasta 2010, en que el Ministerio de Defensa ordenó que fuese trasladada a Bétera cubierta por una lona. (Dossier, El País 7/04/2010).

Otro ejemplo: hasta Marzo de 2005 el Ministerio de Fomento no retiró la estatua ecuestre de Franco sita desde 1959 en la plaza de San Juan de la Cruz del barrio madrileño de Nuevos Ministerios. Tras retirarla, fue depositada en el almacén del Ministerio de Obras Públicas y Urbanismo del distrito de Ciudad Lineal y la titular de Fomento declaró que sería sustituida por un símbolo de concordia entre los españoles (Rodríguez, El Mundo, 17/03/2005). El olvido evasivo de los gobernantes de la Transición Democrática había dado paso a la formación de los mitos de una nueva identidad nacional posfranquista, donde ocupaba un lugar relevante la reconciliación y la europeización. Pero el acontecimiento de 2005 generó una notable expectación entre los españoles tanto detractores como partidarios. Un grupo de personas cantaron el Cara al Sol en torno al pedestal vacío (Dossier, El País, 18/03/2005). Ello es una prueba evidente de que no hay una única memoria en la sociedad y de que cada 
grupo adecua a sus valores e intereses la representación del pasado que elabora. Existe una pluralidad de memorias colectivas vinculadas con las relaciones de poder y en conflicto en la sociedad (Sevillano, 2003).

Una de las primeras víctimas de la política monumental del régimen franquista nada más ganaron la guerra fue el monumento y también el Paseo de los Mártires de la Libertad de Alicante. El Franquismo destruyó lo que le molestaba y convirtió la ciudad, como tantas otras, en un monumento emblema de la victoria y del régimen. Las piedras de aquel monumento siguen hoy en paradero desconocido, igual que los restos de numerosas víctimas de la represión que permanecen en fosas comunes sin identificar y que, a diferencia de los «caídos por Dios y por España» o del príncipe troyano Héctor de la Grecia Antigua, no han conocido la honra del rescate ni el túmulo de la memoria. Han sido víctimas del olvido. Solamente en fechas muy recientes la Ley 52/2007 ha regulado dicha posibilidad también para los vencidos que padecieron persecución o violencia durante la Guerra Civil y la dictadura franquista; y también ha generado una ola memorialística en todos los campos no exenta de controversias, discusiones y enfrentamientos.

Previamente a la ley, los testimonios personales y las historias de vida de los represaliados y sus familias habían sido y son la fuente privilegiada de la historiografía para estudiar la memoria histórica. Asimismo, los familiares de las víctimas, asociaciones y voluntarios financiaron exhumaciones y actos conmemorativos con recursos propios y con poco o ningún apoyo institucional hasta 2002, en que se iniciaron los movimientos de absorción institucional estatal y autonómica (Ferrándiz, 2007).

Una de las peores humillaciones para un ejército derrotado en los tiempos de la civilización griega, que se ha prolongado en el tiempo, era negarle el derecho a recoger a sus muertos y darles sepultura, honrarlos y preservar su memoria. En los versos de la La llíada Homero narra esta amenaza de Aquiles al moribundo Héctor (La llíada, XXII, 345): «Nadie podrá apartar de tu cabeza a los perros, aunque me traigan diez o veinte veces el debido rescate [...]; ni siquiera la venerada madre que te dio a luz te pondrá en un lecho para llorarte, sino que los perros y las aves de rapiña destrozarán tu cuerpo y devorarán tus entrañas $[\ldots]\rangle$; pero los dioses se irritaron ante la impiedad de Aquiles. Protegieron el cuerpo de Héctor de los carroñeros y permitieron que el rey Príamo, 
alumno de Zeus, lo rescatara. Héctor fue adecuadamente cremado, honrado y llorado por los suyos con sus cenizas guardadas en una urna de oro depositada en un hoyo cubierto de grandes piedras y erigieron un túmulo: «Así se celebraron las honras fúnebres de Héctor, domador de caballos» (La Ilíada, XXIV, 804): nos dice Homero como colofón de su obra.

El 8 de Marzo de 1844 fueron fusilados en el Paseo del Malecón de Alicante 24 miembros de la rebelión iniciada en la misma ciudad en defensa del régimen liberal tras la caída del general Espartero, la proclamación de la mayoría de edad de Isabel II y la ocupación del poder por los moderados en el Gobierno isabelino. Uno de los fusilados fue Pantaleón Boné. Previamente, el 14 de Febrero del mismo año ya habían sido fusilados otros partidarios de la misma rebelión en el muro del Panteón de los Guijarro de Villafranqueza, situado en las afueras de la ciudad, y sus cuerpos abandonados en una fosa común sin lápida de identificación.

Las experiencias revolucionarias en defensa de los ideales liberal y progresista fueron continuas en la ciudad de Alicante del siglo XIX, igual que la represión de sus partidarios vencidos y el rescate posterior recurrente de su memoria. La represión de 1844 se convirtió en la más emblemática para los habitantes de la ciudad, que no olvidaron a los muertos y los homenajearon año tras año, tanto con el beneplácito o no de las autoridades. En 1855, ya dentro de la legalidad progresista, la Diputación Provincial de Alicante hizo un monumento portátil de madera coronado con una matrona símbolo de la Libertad para dichos homenajes que se celebraban en el mismo lugar del Malecón donde fueron fusilados y, en el contexto del llamado Sexenio Revolucionario (1868-1874), el Ayuntamiento en la sesión del 30 de octubre de 1868 propuso hacer un monumento estable y se cambió el nombre del Paseo del Malecón por Paseo de los Mártires de la Libertad. Tras años de gestiones con las autoridades portuarias y altibajos financieros, el monumento, obra de Vicente Bañuls, se emplazó en medio del paseo el 8 de marzo de 1907 hasta que se trasladó finalmente al principio del mismo en 1914, donde se encontraba cuando terminó la guerra y fue desmontado (Rosser, 1994). Hoy hay una fuente donde estaba el monumento, en lo que es la plaza del Mar al principio de la Explanada. Nadie lo ha recuperado hasta ahora a pesar de que diversos 
movimientos cívicos lo han intentado tal cual hizo el rey Príamo con Héctor; pero sin el beneplácito de aquellos dioses ni la piedad de los presentes.

Entre el 28 de septiembre y el 8 de octubre de 1981 se celebró una exposición subasta de los artistas alicantinos pro-monumento Mártires de la Libertad en la Sala de Exposiciones de la Mútua Unión Patronal de Alicante. El objetivo era reponer el monumento, pero sin intencionalidad política según las palabras textuales de la hoja de sala de la exposición:

El propósito de reponer el monumento consagrado a la memoria de los Mártires de la Libertad carece de cualquier intencionalidad política. Por el contrario, ansiamos esencialmente recuperar una entrañable tradición del pueblo alicantino en justo homenaje a los 24 patriotas que, alzados en armas contra un gobierno despótico, murieron fusilados [...] / Acudimos a la generosidad de nuestros conciudadanos para que se sumen al nobilísimo gesto de todos los artistas de nuestra querida tierra y a las ayudas valiosas de la Excma. Diputación Provincial de Alicante y del Excmo. Ayuntamiento de nuestra capital / A todos, en nombre de la Comisión Pro-Monumento a los Mártires de la Libertad, gracias. / Alicante, septiembre de 1981.

La iniciativa de los artistas alicantinos fracasó. En 1992 un grupo de vecinos de Villafranqueza creó una comisión para recordar a los fusilados mediante una procesión cívica que culmina en el Panteón de los Guijarro, en cuyos muros fueron fusilados algunos de estos mártires de 1844. Desde entonces se celebra esta procesión cívica todos los años el sábado más cercano al 14 de febrero por iniciativa de este grupo de vecinos. Participan con discursos distintas fuerzas políticas y las autoridades municipales de Alicante, que han prometido recientemente crear un museo dedicado a los Mártires de la Libertad del siglo XIX en dicho panteón, el cual está muy lejos de la plaza del Mar donde se levantó la estatua diseñada por Bañuls en 1907 y retirada por las autoridades municipales franquistas nada más terminada la guerra.

\section{Epílogo}

La Ley 52/2007 dio competencia a la Administración pública para tomar las medidas oportunas para la retirada de escudos, insignias, placas y otros 
objetos o menciones conmemorativas de exaltación de la sublevación militar, la Guerra Civil y la represión de la Dictadura; pero no ha regulado nada sobre la recuperación de la memoria histórica monumental de la ciudad autolesionada por el franquismo.

El 14 de febrero de 2015 en la manifestación cívica de Villafranqueza había poco más de cien personas, de las cuales eran mayoría los representantes de distintas fuerzas políticas y autoridades municipales, incluido el alcalde de Alicante. En la disputa entre la memoria y el olvido, es como si el olvido ganase terreno a la memoria en la arena social una vez institucionalizada la marcha cívica de los Mártires de la Libertad, que rinde homenaje a aquellos hombres de 1844 cuyos huesos siguen en paradero desconocido en algún lugar del suelo donde estaban los muros del Panteón, igual que el monumento ausente de la actual plaza del Mar del que solamente quedan las imágenes de las postales antiguas.

\section{Referencias}

De Seta, C. (2002): La ciudad europea del siglo XV al XX, Ediciones Istmo, Madrid.

Ferrándiz Martín, F.(2007): «Exhumaciones y políticas de la memoria en la España contemporánea», en Hispania Nova. Revista de Historia Contemporánea, $\mathrm{n}^{\mathrm{o}} 7$. En línea $<\underline{\mathrm{http}}$ :/hispanianova.rediris.es $>$.

Ferri, Pablo (2005), «Defensa retira la estatua ecuestre de Franco en Valencia», en El País, 07-04-2005 en línea <http://elpais.com/diario/2010/04/07/espana/1270591218 850215.html $>$.

Homero (1989): La Ilíada, Prólogo de Bernabé, A., Editorial edaf, Madrid.

Llorente Hernández, Á. (2002): Arte e ideología en la España de la postguerra (1939-1951). [Tesis Doctoral] Tesis en CD-ROM, Universidad Complutense de Madrid, Facultad de Geografía e Historia, Departamento de Historia del Arte, 1991.

Rodríguez, D. (2005): «El Gobierno retira la estatua de Franco en Nuevos Ministerios», en El Mundo, 17/03/2005 en línea <http://www.elmundo.es/elmundo/2005/03/17/madrid/1111018865.html $>$.

Rosser Limiñana, P. (1994): «El Paseo y Monumento a los "Mártires de la Libertad"», en Alicante», en LQNT 2, Alicante, pp. 199-218. 
SANTaCreu Soler, J. M. (edr. 2008): Una presó amb vistes al mar. El drama del port d'Alacant, març de 1939, Tres i quatre, València.

Sevillano Calero, F. (2003): «La construcción de la memoria y el olvido en la España democrática», en Ayer, n 52 , pp 297-319.

$B O E$

LEY 52/2007, de 26 de diciembre, por la que se reconocen y amplían derechos y se establecen medidas en favor de quienes padecieron persecución o violencia durante la guerra civil y la dictadura.

Orden de 18 de Febrero de 1938 ( de Estilo en las Conmemoraciones de la Patria

Orden de 7 de Agosto de 1939 ( $B O E$ 22/08/1939) disponiendo que quedase supeditada a la aprobación del Ministerio de la Gobernación toda iniciativa de monumentos en general.

Prensa

Dossier sobre la Retirada la última estatua de Franco en Madrid La figura ecuestre, de siete metros de altura, fue realizada en 1956 por el escultor José Capuz en El País 17 y 18/03/2005 en línea < $\underline{\text { http:// }}$ agonzalez.web.wesleyan.edu/span252/bibliografia/EP 050317 estatua franco.pdf $>$ 